NASA Technical Memorandum 105390

AIAA-92-0773

\title{
Jet Mixing Into a Heated Cross Flow in a Cylindrical Duct: Influence of Geometry and Flow Variations
}

M.S. Hatch, W.A. Sowa, and G.S. Samuelsen

University of California

Irvine, California

J.D. Holdeman

Lewis Research Center

Cleveland, Ohio

Prepared for the

30th Aerospace Sciences Meeting and Exhibit

sponsored by the American Institute of Aeronautics and Astronautics

Reno, Nevada, January 6-9, 1992 
JET MIXING INTO A HEATED CROSS FLOW IN A CYLINDRICAL DUCT: INFLUENCE OF GEOMETRY AND FLOW VARIATIONS

\author{
M.S. Hatch, ${ }^{*}$ W.A. Sowa, ${ }^{* *}$ G.S. Samuelsen $\dagger$ \\ University of California \\ UCI Combustion Laboratory \\ Irvine, California 92717-3550 \\ J.D. Holdemant† \\ National Aeronautics and Space Administration \\ Lewis Research Center \\ Cleveland, Ohio 44135
}

\begin{abstract}
To examine the mixing characteristics of jets in an axi-symmetric can geometry, temperature measurements were obtained downstream of a row of cold jets injected into a heated cross stream. Parametric, non-reacting experiments were conducted to determine the influence of geometry and flow variations on mixing patterns in a cylindrical configuration. Results show that jet to mainstream momentum flux ratio and orifice geometry significantly impact the mixing characteristics of jets in a can geometry. For a fixed number of orifices, the coupling between momentum flux ratio and injector geometry determines (1) the degree of jet penetration at the injection plane, and (2) the extent of circumferential mixing downstream of the injection plane. The results also show that, at a fixed momentum flux ratio, jet penetration decreases with (1) an increase in slanted slot aspect ratio, and (2) an increase in the angle of the slots with respect to the mainstream direction.
\end{abstract}

\section{List of Symbols}

\begin{tabular}{|c|c|c|}
\hline $\mathbf{J}$ & & jet to mainstream momentum flux ratio \\
\hline$\phi$ & & orifice angle with respect to mainstream \\
\hline$f$ & & mixture fraction \\
\hline MR & & jet to mainstream mass ratio \\
\hline & & jet to mainstream density ratio \\
\hline MOD1 & & eight-hole baseline geometry \\
\hline MOD2 & - & $8: 1$ aspect ratio slanted slots, $\phi=45^{\circ}$ \\
\hline MOD3 & - & $4: 1$ aspect ratio slanted slots, $\phi=0^{\circ}$ \\
\hline MOD4 & - & $4: 1$ aspect ratio slanted slots, $\phi=22.5^{\circ}$ \\
\hline MOD5 & - & $4: 1$ aspect ratio slanted slots, $\phi=45^{\circ}$ \\
\hline MOD6 & - & $4: 1$ aspect ratio slanted slots, $\phi=67.5^{\circ}$ \\
\hline MOD7 & - & $4: 1$ aspect ratio slanted slots, $\phi=90^{\circ}$ \\
\hline
\end{tabular}

\section{Introduction}

In recent years, environmental issues have become a growing concern due to the increased public awareness of phenomena such as the green house effect, global warming, and ozone layer depletion. Studies have shown that the combustion systems of mobile and stationary sources generate over $90 \%$ of the pollutant emissions released in the atmosphere. Stringent air quality

\begin{tabular}{ll}
\hline$*$ & Graduate Student Researcher \\
$* *$ & Associate Director, UCICL \\
$\dagger$ & Professor, Corresponding Author \\
& Associate Fellow, ALAA \\
$\dagger \dagger$ & Senior Research Engineer, \\
& Senior Member AIAA
\end{tabular}

Copyright c 1992 by the American Institute of Aeronautics and Astronautics, Inc. No copyright is asserted in the United States under Title 17, U.S. Code. The U.S. Government has a royalty-free license to exercise all rights under the copyright claimed herein for Governmental purposes. All other rights are reserved by the copyright owner. regulations have been proposed and implemented to control the emissions of combustion systems including gas turbine combustors. To meet the air quality standards, efforts have been concentrated on developing low emissions combustors. ${ }^{1}$

One of the promising low $\mathrm{NO}_{\mathrm{x}}$ combustor concepts is the RichBurn/Quick-Mix/Lean-Burn (RQL) combustor. ${ }^{2}$ In this concept, the primary zone is designed to operate rich at an equivalence ratio of 1.2-2.0. The products of combustion, high in carbon monoxide concentrations, then enter the quick mix region and are mixed with the remaining air. The combustion process is completed in the lean-burn zone.

A key to the success of the RQL combustor concept is achieving rapid and uniform mixing in the quick mix region of the combustor. Poor mixing in this section can form near stoichiometric packets at high temperatures, and allow them sufficient time to form large amounts of NO. Non-uniform mixing can also result in hot spots which may severely degrade the combustor liner material.

To contribute to the understanding of the RQL concept, it is important to investigate the mixing mechanisms in the transition region and the role of these processes on NO formation and material integrity.

\section{Background}

Mixing of jets in a confined cross flow has a variety of practical applications and has motivated a number of studies over the past decades. In a gas turbine combustor, for example, mixing of relatively cold air jets is important in the dilution zone where the products of combustion are mixed with air to reduce the temperatures to levels acceptable for the turbine blade material. Mixing of jets in a cross flow is also important in applications such as discharge of effluents in water, and in transition from hover to cruise of V/STOL aircraft.

Most of the previous research of jets in a cross flow has been performed in rectangular geometries. Examples of these studies are provided in Table 1 and summarized elsewhere. ${ }^{3,4}$ The influence of orifice geometry and spacing, jet to mainstream momentum flux ratio, $\mathrm{J}$, and density ratio have been documented for single and double sided injection (e.g., Reference 4). These studies have identified momentum flux ratio (J) and orifice spacing as the most significant parameters influencing the mixing pattern.

The RQL developmental effort has added a new dimension to the study of jet mixing in a confined cross flow. 1,2 More specifically, the range of jet to mainstream mass flow ratios encountered in the quick mix region of a RQL combustor, differ significantly from those of a conventional combustor dilution zone. $5,6,7$

\section{Experiment}

The literature survey of previous mixing studies in rectangular geometries identified the jet to mainstream momentum flux ratio, 
$\mathrm{J}$, and orifice spacing as the primary variables influencing mixing characteristics. A series of parametric experiments were conducted in this study to determine the influence of these variables on mixing of jets in a can geometry. The parametric experiments investigated a range of $\mathrm{J}$ values including 25,52 , and 80 . A jet to mainstream mass ratio of 2.2 was maintained at each tested J value. An area discharge coefficient of 0.80 was assumed in designing the orifices.

The modules tested in the parametric studies were fabricated from a 3-inch $(76 \mathrm{~mm})$ inside diameter, 0.125-inch $(3.18 \mathrm{~mm})$ thick Plexiglas tubing. Plexiglas was selected for its optical quality, and ease of fabrication. For each $J$ value, configurations with eight, equally spaced orifices were evaluated. The geometries included:

- Round holes (Module 1),

- 4:1 aspect ratio slots oriented at various angles with respect to the mainstream flow direction: $0^{\circ}$ (Module 3); $22.5^{\circ}$ (Module 4); $45^{\circ}$ (Module 5); $67.5^{\circ}$ (Module 6); and $90^{\circ}$ (Module 7),

- $8: 1$ aspect ratio slots oriented at $45^{\circ}$ (Module 2).

The modules were 6.5 -inch $(165 \mathrm{~mm})$ long, with the center of the orifice row placed at one radius from the edge. The orifice area for each module at the design J value was kept constant. As a result, the dimensions of a given orifice varied as a function of J. Schematics of the modules are provided in Figures 1 through 3. Note that high angle configurations consume more space than available for a given orifice size and cannot be fabricated. As a result, there are no 75 - or 90 -degree slots for $\mathrm{J}=25$, nor a 90 degree slot for $\mathrm{J}=52$. While the leading edge of each orifice was fixed at the same axial location $(Z / R=0.0)$, the axial extent of jet mass addition varied according to orifice size and, in the case of the slots, slot angle and slot aspect ratio as well. For reference, the axial location of the trailing edge and blockage are presented in Table 2. The former is expressed as the ratio of the axial projection of the orifice to the radius of the mixing module, and the latter is defined as the ratio of the circumferential projection of the orifice to the spacing between orifice centers.

Mixing was examined by recording the mean temperature distribution downstream of the injection plane. The mainstream flow entering the module was heated to the highest temperature

$\left(212^{\circ} \mathrm{F}\right)$ compatible with the upper temperature limits of Plexiglas. Jets were introduced at room temperature.

The operating conditions are presented in Table 3. Reference velocity, defined as the velocity at the inlet to the mixing section and calculated based on the mainstream temperature and pressure, was $34.5 \mathrm{fps}(10.5 \mathrm{~m} / \mathrm{s})$. The actual discharge coefficient, and momentum flux ratio for each case was determined by measuring the jet pressure drop.

A 12 -inch long, 0.125 -inch type $\mathrm{K}$ thermocouple was used to measure the temperatures. The thermocouple was held in a fixed position while the test stand traversed in $\mathrm{X}, \mathrm{Y}$, and $\mathrm{Z}$ directions. The probe was positioned in the center with respect to four, $90^{\circ}$ apart, reference points marked on each module. Temperature was measured at 50 points in a quarter sector of the modules, for five planes downstream of the orifices. Figures $4 \mathrm{a}$ and $4 \mathrm{~b}$ show the measurement points and the axial planes. A $90^{\circ}$ sector was selected to examine the interaction of the adjacent jets and the asymmetries of the flow field. The five planes examined in this study were located between $Z / R=0.08$, and $Z / R=1.0$ where $Z$ was measured from the leading edge of the orifices. Temperature distributions were recorded using a Fluke temperature readout (Model 2160A). A Beckman temperature indicator (Model 500T) was used to monitor the mainstream and jet temperatures. Note that the axial projection of the orifice centers for all the modules tested were at the $22.5^{\circ}$ and $67.5^{\circ}$ locations in this quadrant.

\section{Experimental Facility}

An atmospheric test facility located at the UCI Combustion Laboratory was used to conduct the mixing experiments. The facility was designed to provide high air flow rates as well as preheat capabilities. The house air, was filtered and regulated before branching into two isolated main and jet circuits. The jet circuit incorporated four independently metered flow legs. The main circuit consisted of a coarse and a fine leg which provided a total of 150 SCFM for the mainstream flow. Each leg was regulated independently to eliminate the effects of pressure fluctuations. All circuits were metered by sonic venturies. The mainstream air was heated to $200^{\circ} \mathrm{F}$ by a $20 \mathrm{~kW}$ air preheater (Watlow, P/N 86036-2). The outlet temperature was monitored by a type $\mathrm{J}$ thermocouple and controlled by a heater controller (Watlow, series 800).

Figure 5 shows a schematic of the test facility. The mainstream air, metered and heated, was passed through a 2 -inch insulated carbon steel pipe to the vertically mounted test bed. A combination honeycomb/screen provides uniform flow at the inlet to the mixing module. A five-foot long section of $2^{\prime \prime}$ flexible tubing was provided immediately upstream of the test setup to facilitate traversing the experiment in the $\mathrm{X}, \mathrm{Y}$, and $\mathrm{Z}$ directions. The test stand was traversed manually, and a Mitutoya model PM-331 digital traverse readout was used to read the coordinates.

The 3-inch mixing section used in the parametric phase was positioned inside a concentric Pyrex manifold as shown in Figure 6. The manifold had a 5.5 -inch $(140 \mathrm{~mm})$ outside diameter with a wall thickness of 0.125 -inches $(3.18 \mathrm{~mm})$. The jet manifold incorporated four openings on top and four on the bottom, each $90^{\circ}$ apart, and placed 1 inch from the edges. Four discrete jets were supplied at right angle to the manifold through the bottom openings. Two of the openings on the top were used to measure the manifold temperature and pressure, and the other two were blocked. Each jet circuit was metered individually, and equal lengths of silicone tubing between the flow control panel and the test section were used to provide symmetric flow conditions at the inlet to the manifold. A 1-inch thick, doughnut shaped honeycomb section installed upstream of the orifices, provided uniform flow at the injection point.

\section{Analysis}

To compare the mixing characteristics of different modules, the temperature measurements were normalized by defining the mixture fraction, $f$, at each point in the plane:

$$
f=\frac{T_{\text {measured }}-T_{\text {jet }}}{T_{\text {main }}-T_{\text {jet }}}
$$

A value of $f=1.0$ corresponds to the mainstream temperature, while $f=0$ indicates the presence of the pure jet flow. Complete mixing occurs when $f$ approaches the equilibrium value which is nearly equal to the ratio of the upstream flow to the total flow. Note that $f=1-\theta$, where $\theta$ appears often in previous studies. ${ }^{4}$

To quantify the mixing effectiveness of each module configuration, an area-weighted standard deviation parameter ("Mixture Uniformity") was defined at each Z/R plane:

$$
\text { Mixture Uniformity }=\sqrt{\frac{1}{\mathrm{~A}} \sum_{\mathrm{i}=1}^{\mathrm{n}} \mathrm{a}_{\mathrm{i}}\left(f_{\mathrm{i}}-f_{\text {equil }}\right)^{2}}
$$


Where: $\quad \mathrm{A}=\sum \mathrm{a}_{\mathrm{i}}, f_{\mathrm{i}}$ is the mixture fraction calculated for each node, and $f_{\text {equil }}$ is the equilibrium mixture fraction, defined as:

$$
f_{\text {equil }}=\frac{T_{\text {equil }}-T_{\text {jet }}}{T_{\text {main }}-T_{\text {jet }}}
$$

Complete mixing is achieved when the mixture uniformity parameter across a given plane reaches zero.

\section{Results and Discussion}

This section presents the mixing characteristics for the baseline geometry (Module 1), and the $8: 1$ and $4: 1$ slanted slots configurations (Module 2, and Module 5) as a function of momentum flux ratio. In addition, the effects of slot aspect ratio and orientation on mixing pattern are discussed. From a overallmixing standpoint, an optimum mixer is defined as one that produces a uniformly mixed flow field, without a persistent unmixed core or unmixed circumferential regions, by the $\mathrm{Z} / \mathrm{R}=1.0$ plane. In the contour plots presented, the center of the jets are located at $22.5^{\circ}$ and $67.5^{\circ}$ relative to the measurement plane. For slanted slots, the jets angle counter-clock-wise as move upstream, and clock-wise as move downstream.

Module 1 -- Baseline Geometry (holes). Three baseline geometries were tested as part of the parametric experiments. Figures 7,8 , and 9 present the mixture fraction variations between planes $\mathrm{Z} / \mathrm{R}=0.0$ to $\mathrm{Z} / \mathrm{R}=1.0$ for the three momentum flux ratios: $J=25,52$, and 80 (cases J25MOD1, J52MOD1, and J80MOD1). The actual $\mathrm{J}$ is shown in the figure caption.

A comparison of the mixture fraction distribution at the first axial location $(\mathrm{Z} / \mathrm{R}=0.0)$ shows a decrease in $f$ at the center, with increasing momentum flux ratio. For $\mathrm{J}=25$ (J25MOD1), $f$ is in the range of $0.8-0.9$ at the core of the module, indicating the penetration of some jet fluid to the center. For $\mathrm{J}=52$ (J52MOD1), and $\mathrm{J}=80$ (J80MOD1), the mixture fraction values at the center are $0.3-0.4$, and $0.2-0.3$, respectively. These $f$ values are at or below fequil, indicating over-penetration to the center.

At the jet injection locations for $\mathrm{J}=25$ (J25MOD1), $f$ decreases monotonically in the radial direction, with the highest concentration on the duct centerline $(R=0.0)$, and lowest at the walls $(R=1.5)$. The monotonic variation of $f$, indicates that no back flow exists for this configuration. The radial variation of $f$ at $\mathrm{Z} / \mathrm{R}=0.0$ for $\mathrm{J}=52$ (J52MOD1), and $\mathrm{J}=80$ (J80MOD1), on the other hand, is non-monotonic. For these modules, at the injection location, $f$ is relatively low at $R=0.0$, initially increases as $\mathrm{R}$ is increased, and approaches zero at the jet inlet. This non-monotonic variation of $f$ indicates back flow and overpenetration of jets for these configurations.

Over-penetration of jets is evident at the downstream axial locations for $\mathrm{J}=52$ (J52MOD1), and $\mathrm{J}=80$ (J80MOD1), by the high concentration of $f$ near the wall. At $Z / R=1.0$, both $\mathrm{J}=52$ (J52MOD1) and $\mathrm{J}=80$ (J80MOD1) show low $f$ values at the center, and unmixed region along the walls, while $\mathrm{J}=25$ (J25MOD1) shows a more uniformly mixed flow field. The degradation in mixing for $\mathrm{J}=52$ (J52MOD1), and $\mathrm{J}=80$ (J80MOD1), occurs because the increased jet penetration to the module center directs a larger portion of the jet flow to the core, thus decreasing the circumferential mixing along the walls. In an axis-symmetric can geometry, where the majority of the mass is concentrated along the walls, good circumferential mixing is important in obtaining a well mixed flow field. Therefore, according to the definition presented earlier, the round holes at $\mathrm{J}=25$ (J25MOD1) approaches the optimum overall mixer at $\mathrm{Z} / \mathrm{R}=1.0$, among the baseline geometries tested. Following the methodology of Reference 4, the optimum momentum flux ratio for this case would be just over 20 .

Figure 10 compares the mixture uniformity parameter for the baseline modules as a function of momentum flux ratio. This plot confirms the qualitative observation that the increase in the momentum flux ratio improves mixing at the initial planes, but degrades the overall mixing downstream of the injection plane.

Module 2 -- $\left(8: 1\right.$ slots; $\left.45^{\circ}\right)$. Three $8: 1$ aspect ratio geometries were examined during the parametric studies. Figures 11, 12, and 13 present the mixture fraction distribution for these geometries.

The first axial location $(\mathrm{Z} / \mathrm{R}=0.0)$ examined for $\mathrm{J}=25$ (J25MOD2), shows a large region at $f>0.9$, indicating very small or no jet penetration to the center. For this configuration, the relatively unmixed core persists with increasing $\mathrm{Z} / \mathrm{R}$, and is present at the last axial location of $\mathrm{Z} / \mathrm{R}=1.0$. This configuration represents an under-penetrated case.

The presence of unpenetrated mainstream fluid is evident at the first axial location for J=52 (J52MOD2) as well. Due to the increased jet momentum, however, the unpenetrated region is smaller compared to $\mathrm{J}=25$ (J25MOD2). The relatively unmixed core, similar in size and strength to that of $\mathrm{J}=25$ (J25MOD2), is observed in downstream locations, indicating that the increase in momentum flux ratio has not significantly altered the overall mixing.

The first indication of jet penetration to the center, is observed at the $\mathrm{Z} / \mathrm{R}=0.0$ plane of $\mathrm{J}=80$ (J80MOD2). The mixture fraction value at the core of this plane ranges between $0.8-0.9$ indicating that a portion of jet fluid is mixed with the mainstream. At the $\mathrm{Z} / \mathrm{R}=1.0$ plane, the main portion of the flow is at the equilibrium value, while a slightly larger $f$ is seen at the center. The presence of the slightly warmer core shows that this configuration is still slightly under-penetrated. Mixing characteristics of this module are similar to those at $\mathrm{J}=25$ (J25MOD1).

Figures 14 compares the mixture uniformity parameter for the $8: 1$ aspect ratio geometries. At the first axial location, $\mathrm{J}=25$ (J25MOD2) produces degraded mixing due to underpenetration. For increased J values, mixing at the first axial location is improved. The mixing performances at $\mathrm{J}=52$ (J52MOD2), and $\mathrm{J}=80$ (J80MOD2) are similar at the initial axial planes. Beyond $\mathrm{Z} / \mathrm{R}=0.2$, however, $\mathrm{J}=80$ (J80MOD2) clearly produces the better mixing.

Module 5--(4:1 slots; $\left.45^{\circ}\right)$. Figures 15,16 , and 17 present the mixture fraction distribution for the $4: 1$ slots. The first axial location for $\mathrm{J}=25$ (25MOD5 at $\mathrm{Z} / \mathrm{R}=0.0$ ) shows a relatively large central region with mixture fraction values in the range of 0.8 0.9 . This $f$ value is less than unity, indicating slight jet penetration and mixing at the center of the module. Compared to the round hole jets (J25MOD1), however, the region of near unity values of $f$ is larger. The jet penetration for the baseline geometry is stronger at this J value, therefore, the high mixture fraction region is smaller. As described previously, the 8:1 aspect ratio module at $\mathrm{J}=25$ (J25MOD2) represents a case of under-penetration with central $f$ values above 0.9 . At downstream locations, $\mathrm{J}=25$ (J25MOD5) produces a relatively well mixed flow field with no indication of unmixed walls. At $\mathrm{Z} / \mathrm{R}=1.0$, however, a slightly unmixed core is observed.

As $\mathrm{J}$ is increased, the penetration to the center is enhanced and the mixture fraction values at the core of the module at initial axial locations decreases. As previously observed for $\mathrm{J}=52$ for the round jets (J52MOD1), the increase in jet penetration degrades the mixing along the walls. For the $45^{\circ} 4: 1$ aspect ration slots at $\mathrm{J}=52$ (J52MOD5), the circumferential mixing is slightly reduced, resulting in relatively unmixed wall regions. This degradation in mixing along the walls, is less severe for this module compared to $\mathrm{J}=52$ (J52MOD1) due to the presence of the swirling flow induced by the geometry of the module.

At $\mathrm{J}=80$ (J80MOD5), a relatively low $f$ value region is seen at 
the first axial location. At downstream locations, a cool center and relatively unmixed regions along the walls are produced. At this momentum flux ratio as well as at $\mathrm{J}=52$ (J52MOD5), the jets over penetrate, a condition that is not desirable from a over-all mixing standpoint.

Figure 18 compares the mixture uniformity parameter for the $4: 1$ aspect ratio geometries. The trend is very similar to that described for the baseline modules. At initial planes, the higher the momentum flux ratio, the better the mixture uniformity. At downstream locations, the J value with the most initial overpenetration (80), is the poorer mixer due to degradation of circumferential mixing (J80MOD5).

\section{Effect of Slot Aspect Ratio and Angle on Mixing Pattern}

The slot aspect ratio affects (1) the amount of jet mass injected per unit length, and (2) the axial extent over which mass is injected.

For a given momentum flux ratio and number of orifices, the smaller aspect ratio slots penetrate further into the cross stream. The larger aspect ratio slots on the other hand, produce a stronger swirl component and enhances the circumferential mixing. Figure 19 compares the mixture uniformity parameter for the $8: 1$ and $4: 1$ aspect ratio slots. At the lower and intermediate $\mathrm{J}$ values, the $4: 1$ aspect ratio geometry is a better mixer at all axial locations. At the highest $\mathrm{J}$ value tested however, the 8:1 aspect ratio behaves as the better mixing geometry beyond $\mathrm{Z} / \mathrm{R}=0.5$. This is because of the overpenetration of jets at $\mathrm{J}=80$ (J80MOD5) which improve mixing at the initial planes, but produces unmixed regions along the walls at downstream axial locations.

The slot angle affects (1) the axial length over which jet mass is injected, and (2) the "blockage" that the jets present to the cross flow. For illustration, results are presented for the following four 4:1 aspect ratio modules tested at the intermediate value of $\mathrm{J}$ (52): $0^{\circ}$ (J52MOD3), $22.5^{\circ}$ (J52MOD4), $45^{\circ}$ (J52MOD5), and $67.5^{\circ}$ (J52MOD6) with respect to the mainstream direction.

The mixture fraction distribution plots for $0^{\circ}$ (J52MOD3), $22,5^{\circ}$ (J52MOD4), and $67.5^{\circ}$ (J52MOD6) are shown in Figures 20, 21 , and 22 , respectively. The corresponding plot for $45^{\circ}$ (J52MOD5) can be found in Figure 16.

Examining the flow field at the first axial location for these modules shows that by increasing the slots angle, the jet penetration decreases. The swirl component, and the circumferential mixing on the other hand improves by the increase in the slots angle.

The increased jet penetration at the initial axial location, enhances the mixture uniformity as shown in Figure 23. It can be seen that $67.5^{\circ}$ slots (J52MOD6) have the highest mixture uniformity parameter at this location. The $0^{\circ}$ slots (J52MOD3), on the other hand, produce the most jet penetration and the lowest mixture uniformity parameter at $\mathrm{Z} / \mathrm{R}=0.0$. Further downstream the geometry with the most penetration behaves as a poor mixer due to unmixed wall regions.

\section{Conclusions}

- Jet to mainstream momentum flux ratio $(\mathrm{J})$, and orifice geometry significantly impact the mixing characteristics of jets in a cylindrical geometry.
- For a given number of orifices, the coupling between $\mathrm{J}$ and orifice geometry determines the extent of penetration and circumferential mixing in an can configuration.

- From an overall-mixing standpoint, moderate penetration to the center is desirable. Underpenetration forms a relatively unmixed core that persists at downstream locations. Over-penetration degrades circumferential mixing and forms unmixed regions along the walls.

- Increasing the aspect ratio of slanted slots, reduces jet penetration to the center and enhances mixing along the walls.

- Increasing the angle of the slots with the respect to the mainstream also reduces jet penetration and enhances circumferential mixing.

\section{Acknowledgement}

This work is an integral component of a program supported by the NASA-Lewis Research Center (Grant NAG3-1110).

\section{References}

1. Shaw, R.J., "Engine Technology Challenges for a $21 \mathrm{st}$ Century High Speed Civil Transport," ALAA Tenth International Symposium on Air Breathing Engines, September 1-6, 1991 (also NASA TM 104363).

2. Novick, A.S., and Troth, D.L., "Low NOx Heavy Fuels Combustor Concept Program," DDA-EDR-10594, Detroit Diesel Allison Division, General Motors Corporation, Oct 1981 (NASA CR-165367; DOE-NASA-014B-1).

3. Hatch, M.S., Sowa, W.A., and Samuelsen, G.S., "Influence of Geometry and Flow Variation on Jet Mixing and NO Formation in a Model Staged Combustor Mixer", 1992, NASA CR 189094.

4. Holdeman, J. D., " Mixing of Multiple Jets with a Confined Subsonic Crossflow," AIAA-91-2458, 27th Joint Propulsion Conference, Sacramento, CA., June 24-27, 1991 (also NASA TM104412).

5. Smith, C. E., and Talpallikar, M. V., "A CFD Study of Jet Mixing in Reduced Areas for Lower Combustor Emissions," AIAA-90-2460, 27th Joint Propulsion Conference, Sacramento, CA., June 24-27, 1991 (also NASA TM 104411).

6. Talpallikar, M.V., Smith, C.E., Lai, M.C., and Holdeman, J.D., "CFD Analysis of Jet Mixing in Low NOx Flametube Combustors," ASME Paper 91-GT-217, Orlando, FL, June 1991 (also NASA TM 104466).

7. Vranos, A., Liscinsky, D.S., True, B., and Holdeman, J.D. "Experimental Study of Cross-Stream Mixing in a Cylindrical Duct," AIAA Paper 91-2459, Sacramento, CA., June 24-27, 1991 (also NASA TM 105180). 
Table 1: Summary of Selected Jet Mixing Studies

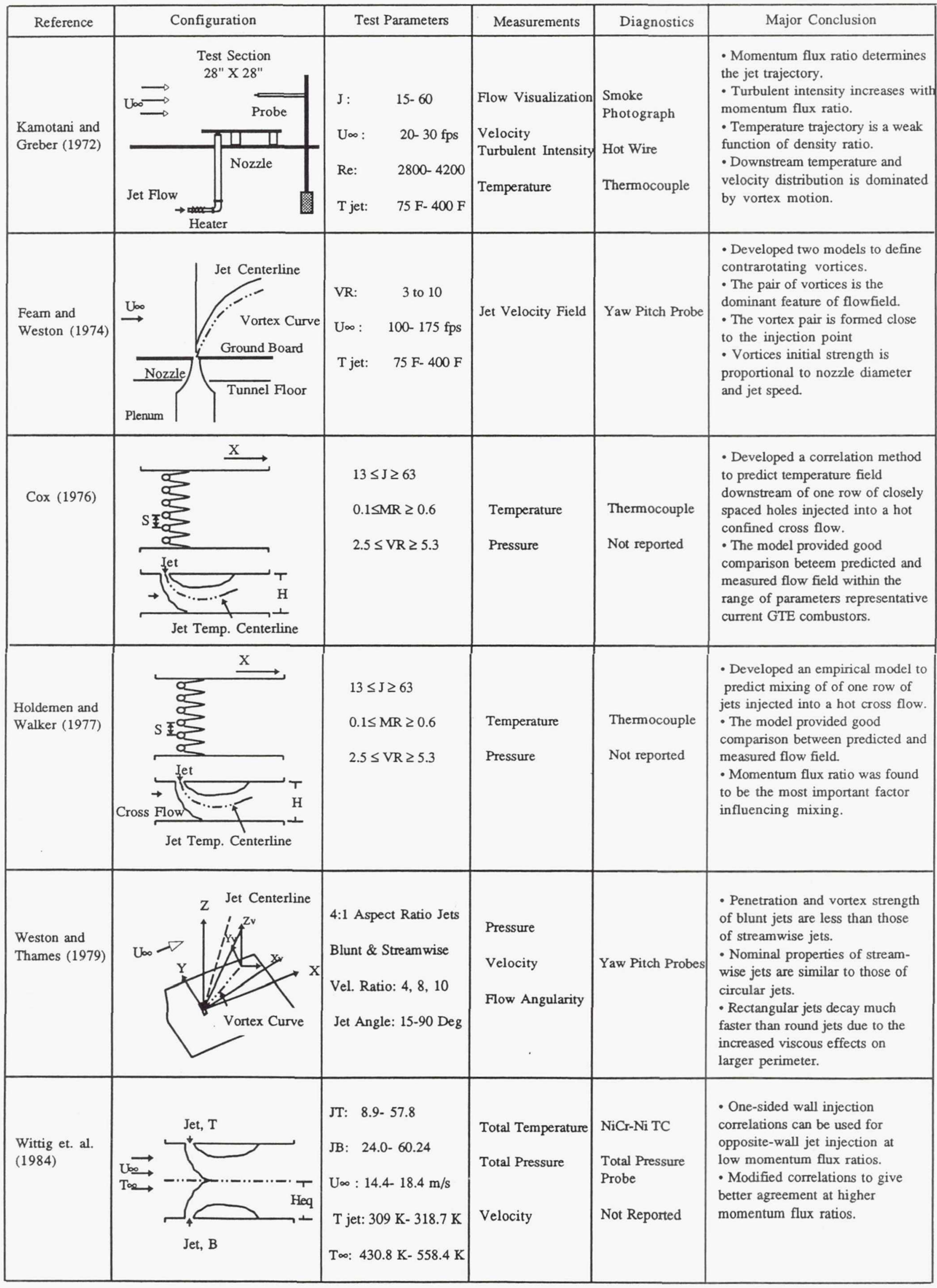


Table 1 Continued

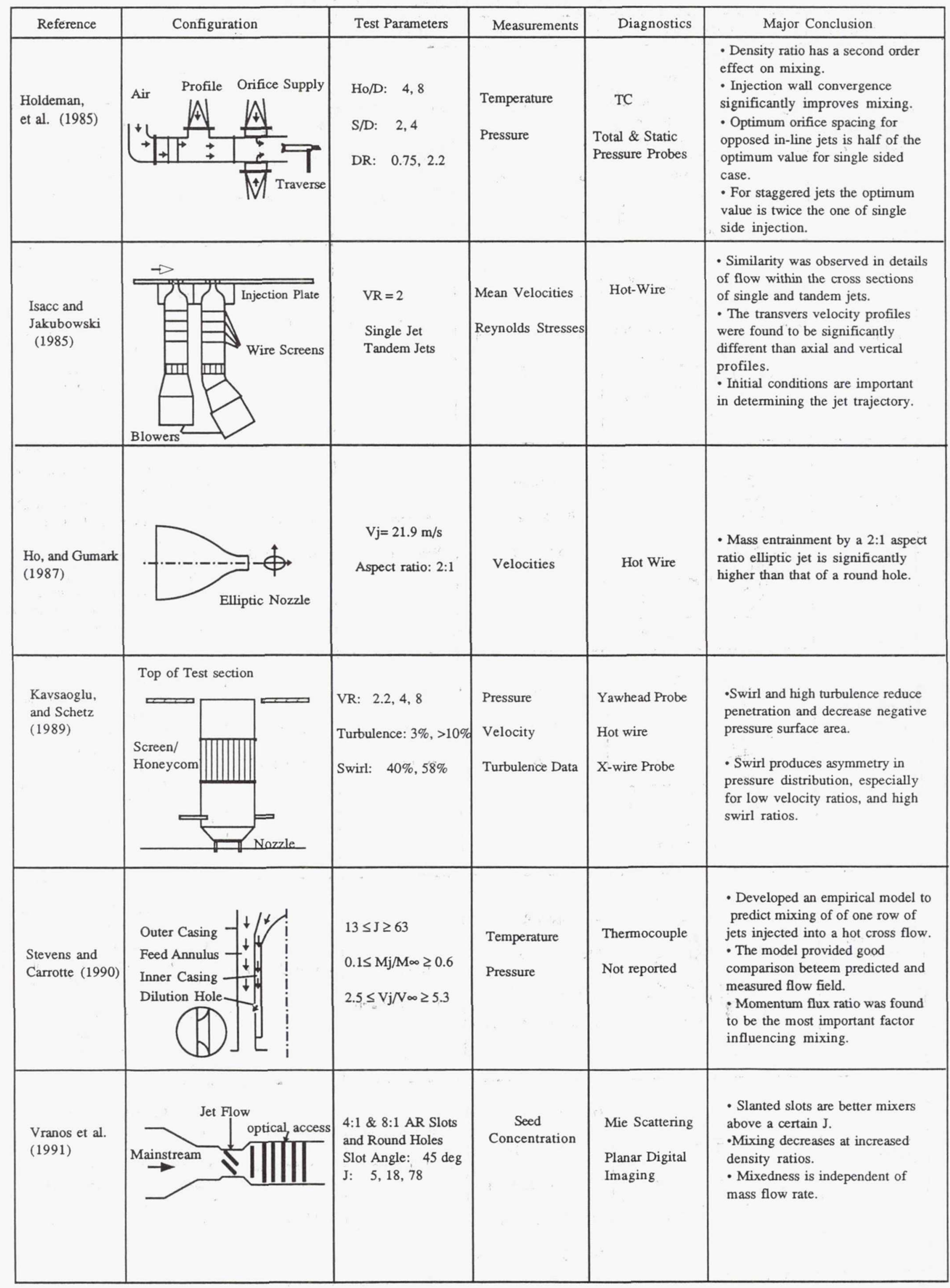


Table 2. Axial Location of Trailing Edge, and Blockage

\begin{tabular}{llclllllllll} 
& & & \multicolumn{4}{c}{$\begin{array}{c}\text { Axial Projection/ } \\
\text { Radius of Mixing Module }\end{array}$} & \multicolumn{4}{c}{$\begin{array}{c}\text { Circumferential Projection/ } \\
\text { Spacing Between Orifice Centers }\end{array}$} \\
\hline Module & Hole/Slot & Aspect Ratio & Angle & $\mathrm{J}=25$ & $\mathrm{~J}=52$ & $\mathrm{~J}=80$ & $\mathrm{~J}=25$ & $\mathrm{~J}=52$ & $\mathrm{~J}=80$ \\
\hline 1 & Hole & -- & -- & 0.50 & 0.42 & 0.37 & 0.64 & 0.53 & 0.48 \\
2 & Slot & $8: 1$ & 45 & 0.93 & 0.78 & 0.70 & 1.19 & 0.99 & 0.89 \\
3 & Slot & $4: 1$ & 0 & 0.90 & 0.75 & 0.67 & 0.29 & 0.24 & 0.21 \\
4 & Slot & $4: 1$ & 22.5 & 0.85 & 0.70 & 0.64 & 0.62 & 0.51 & 0.46 \\
5 & Slot & $4: 1$ & 45 & 0.70 & 0.58 & 0.53 & 0.90 & 0.74 & 0.67 \\
6 & Slot & $4: 1$ & 67.5 & -- & 0.40 & 0.36 & -- & 0.90 & 0.81 \\
7 & Slot & $4: 1$ & 90 & -- & -- & 0.17 & -- & -- & 0.86 \\
& & & & & & & & & & \\
\hline
\end{tabular}

Table 3. Operating Conditions

\begin{tabular}{ccccccc}
\hline $\begin{array}{c}\mathrm{T}_{\text {main }} \\
\left({ }^{\circ} \mathrm{F}\right)\end{array}$ & $\begin{array}{c}\mathrm{T}_{\text {jet }} \\
\left({ }^{\circ} \mathrm{F}\right)\end{array}$ & $\begin{array}{c}\mathrm{P} \\
(\mathrm{psia})\end{array}$ & $\begin{array}{c}\mathrm{V}_{\text {main }} \\
(\mathrm{fps})\end{array}$ & $\begin{array}{c}\mathrm{M}_{\text {main }} \\
(\mathrm{pps})\end{array}$ & $\mathrm{MR}$ & $\mathrm{DR}$ \\
\hline 212 & 74 & 14.7 & 34.5 & 0.10 & 2.2 & 1.26 \\
\hline
\end{tabular}




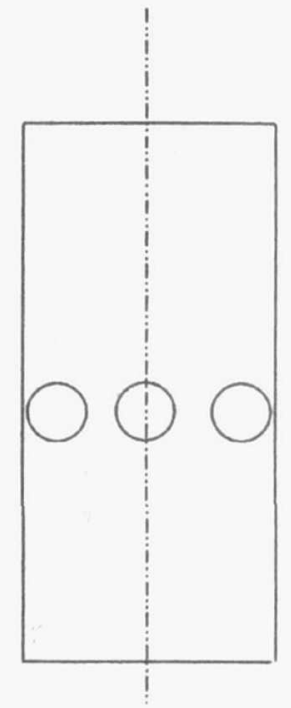

Module 1

Baseline Geometry

Bia.: 0.75 "

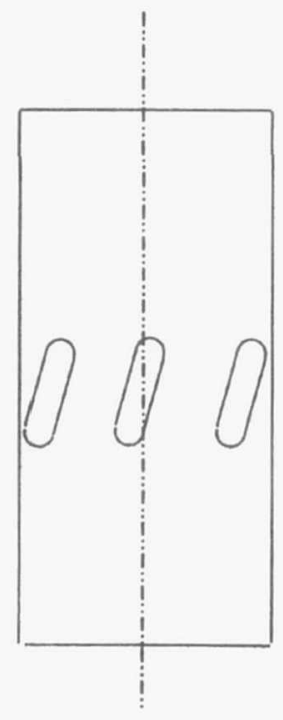

Module 4

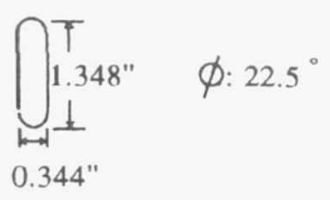

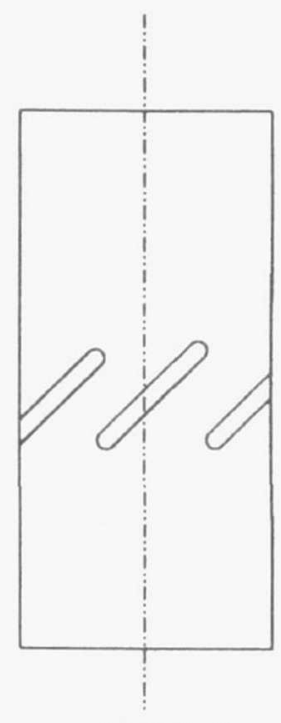

Module 2

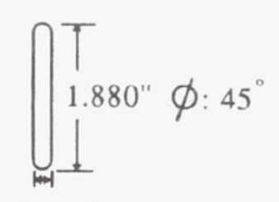

$0.234^{\prime \prime}$

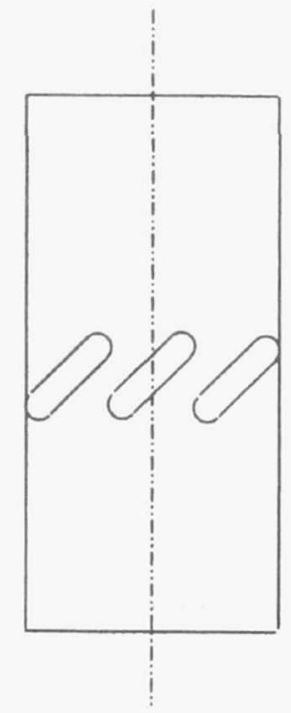

Module 5

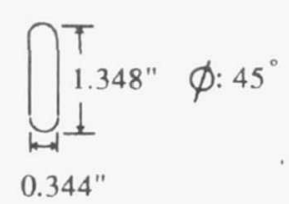

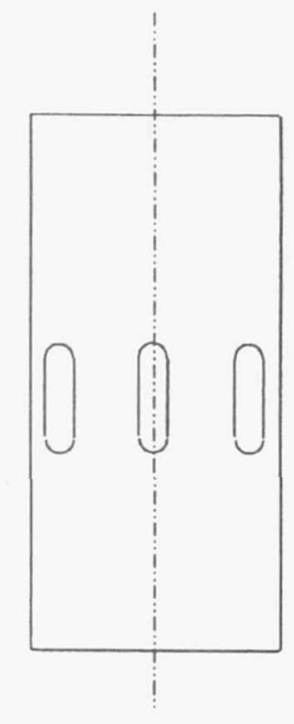

Module 3

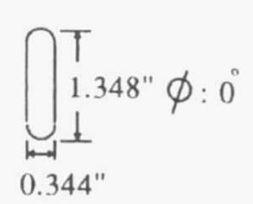

Figure 1: Schematic of Modules for $\mathrm{J}=25$

8 


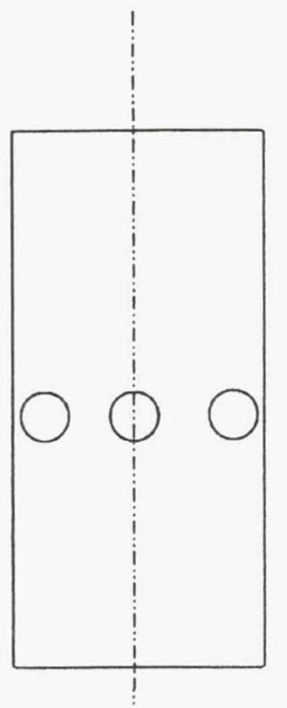

Module 1

Baseline Geometry

$\bigcirc$ Dia.: 0.625 "

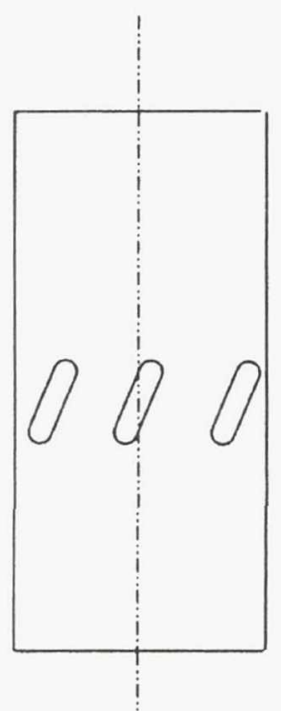

Module 4

$\bigcap_{\substack{k+1 \\ 0.281^{\prime \prime}}}^{\top} 1.120^{\prime \prime} \phi: 22.5^{\circ}$

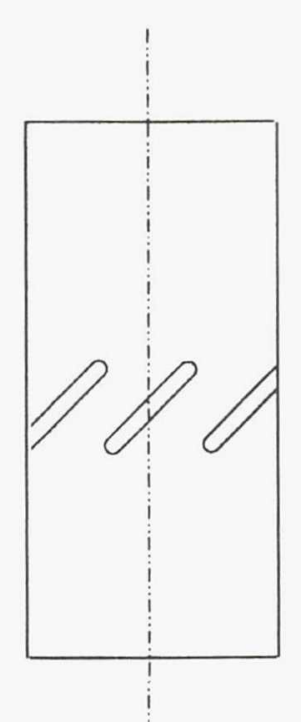

Module 2
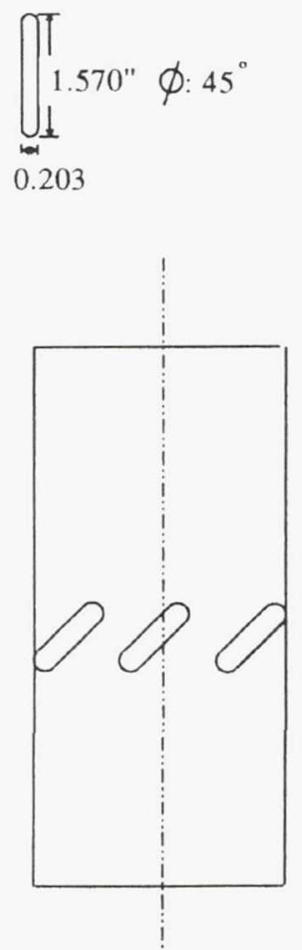

Module 5

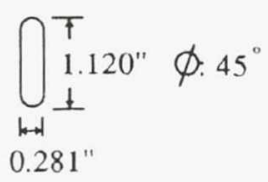

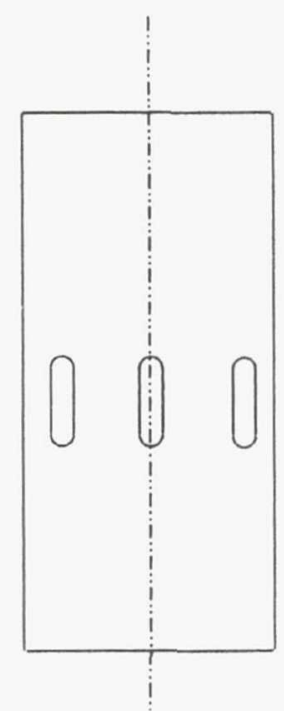

Module 3
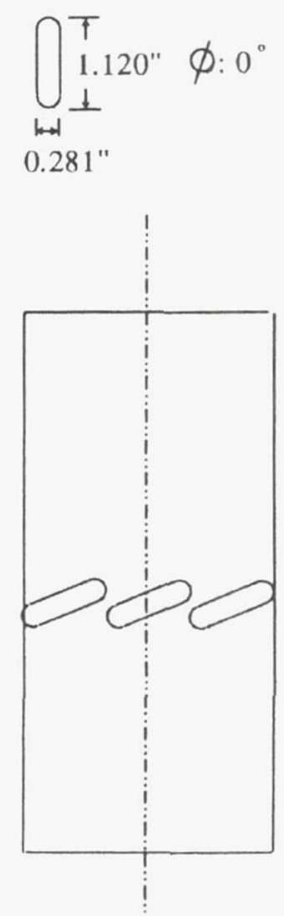

Module 6

$\bigcap_{\substack{\boldsymbol{t} \\ 0.281^{\prime \prime}}}^{\top} 1.120^{\prime \prime} \phi: 67.5^{\circ}$

Figure 2: Schematic of Modules for $\mathrm{J}=52$ 


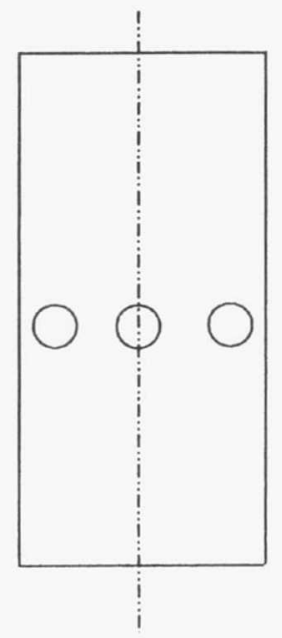

Module 1

Baseline Geometry

$\bigcirc$ Dia.: $0.562 "$

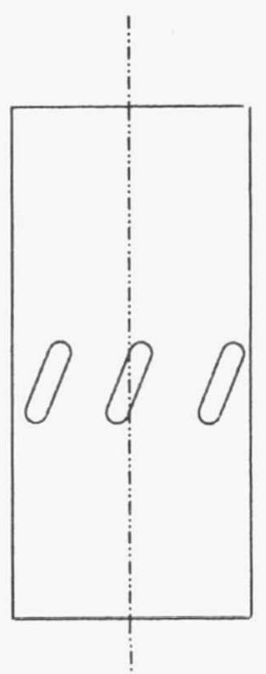

Module 4

$\bigcup_{m+1}^{\top} 1.010^{\prime \prime} \phi: 22.5^{\circ}$

$0.250^{\prime \prime}$

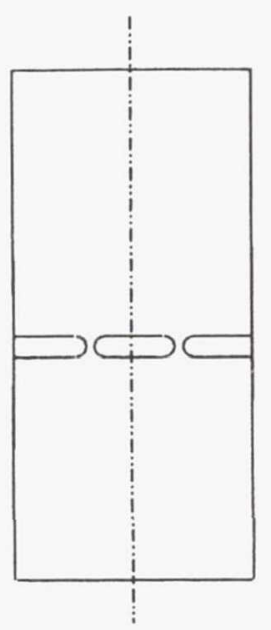

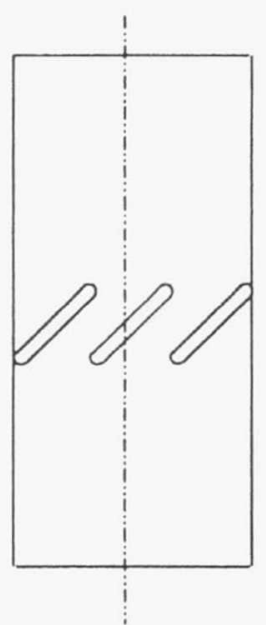

Module 2
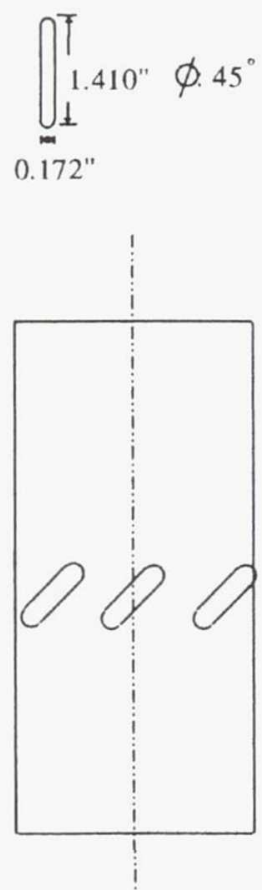

Module 5

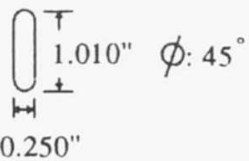

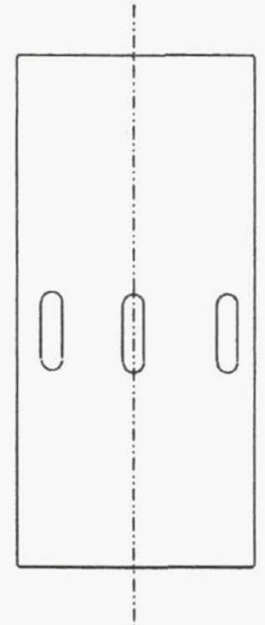

Module 3
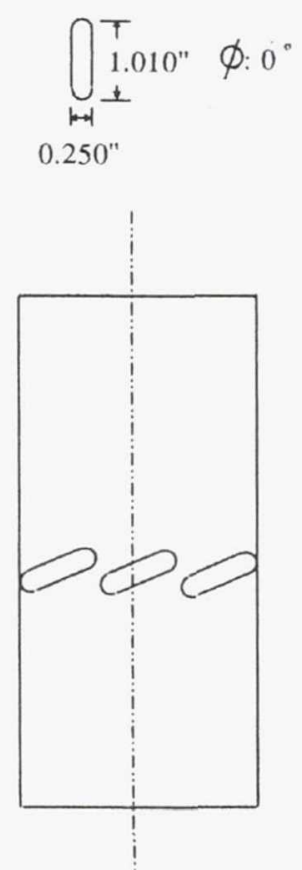

Module 6

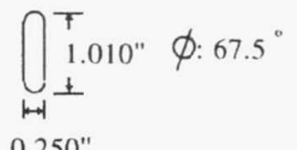

$0.250^{\prime \prime}$

Module 7

$\bigcup_{k=1}^{\top} 1.010^{\prime \prime} \phi: 90^{\circ}$

Figure 3: Schematic of Modules for $\mathrm{J}=80$ 
4a: Points

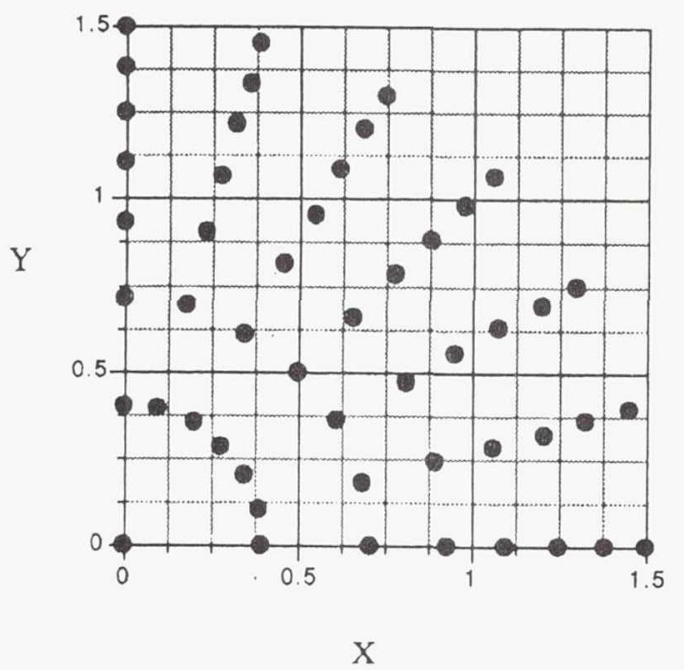

4b: Planes

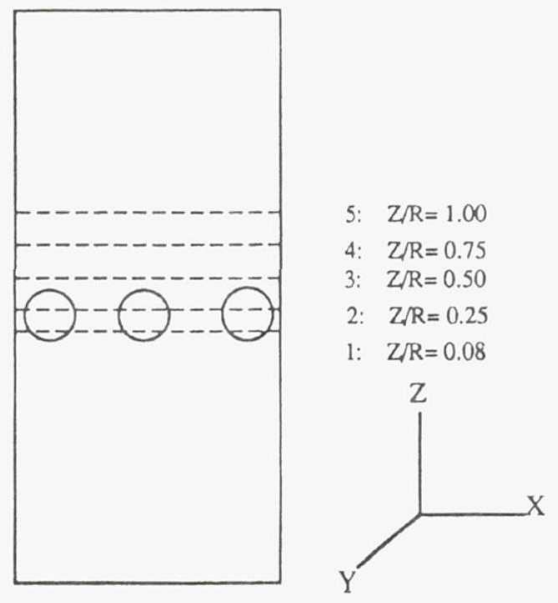

Figure 4: $\quad$ Measurement Points and Planes

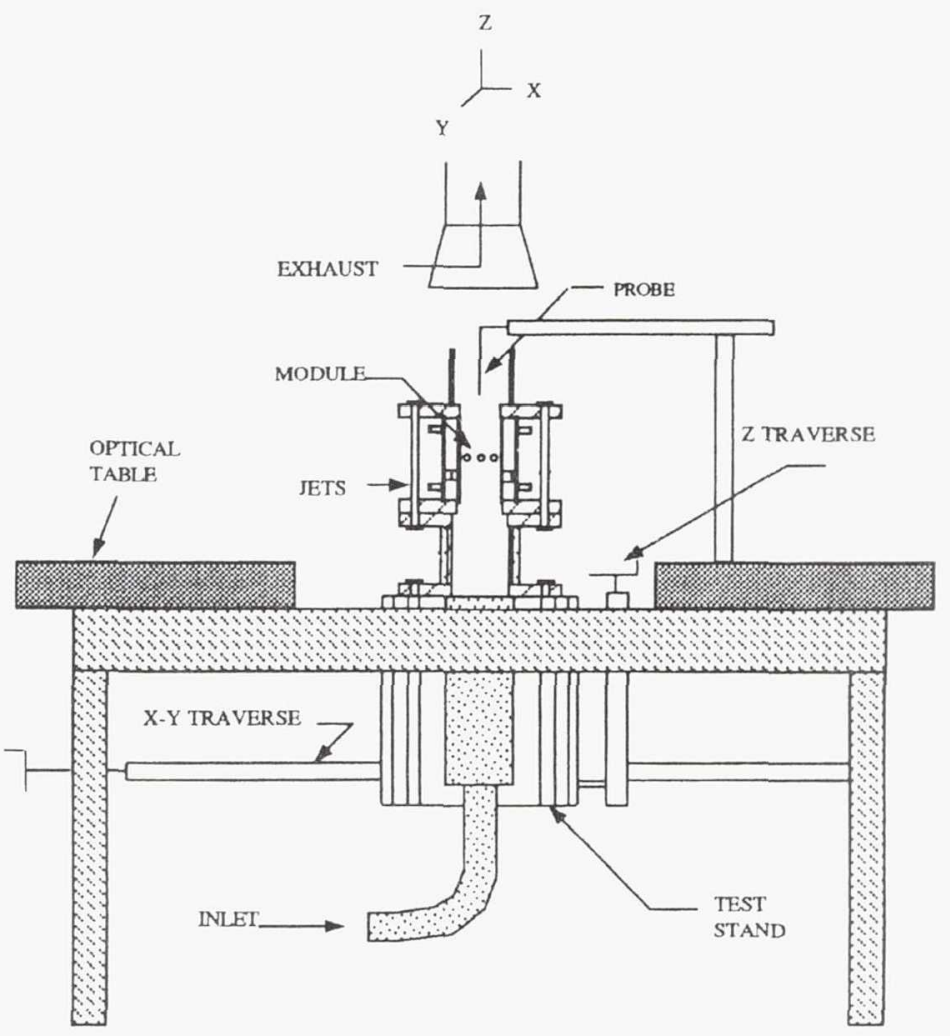

Figure 5: Schematic of the Test Facility 
Page intentionally left blank 

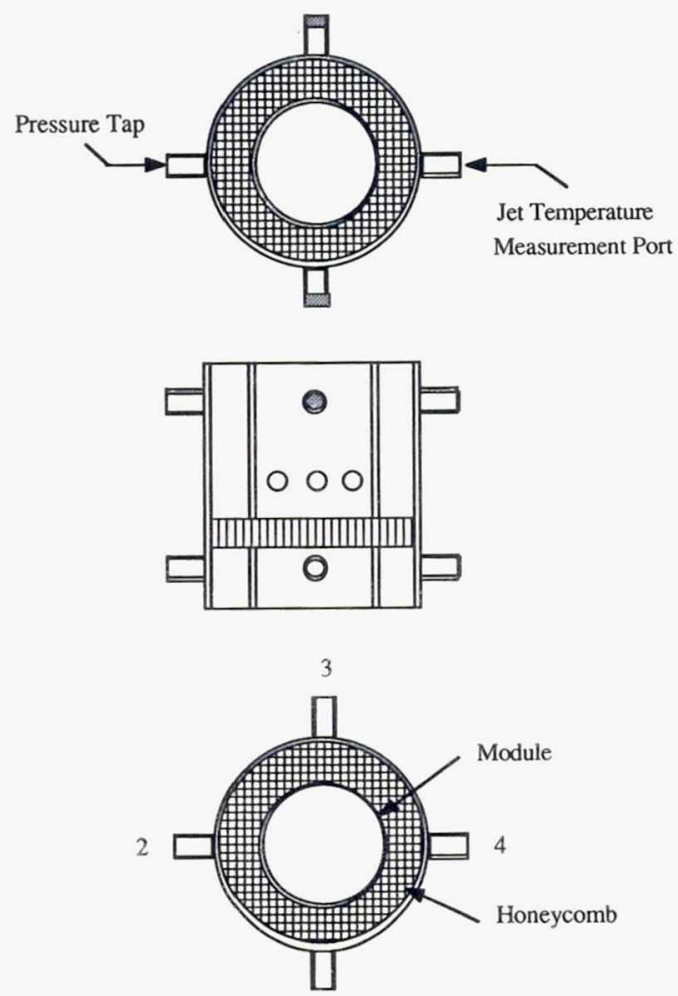

Jet Circuit
1

Figure 6: Schematic of the Test Section

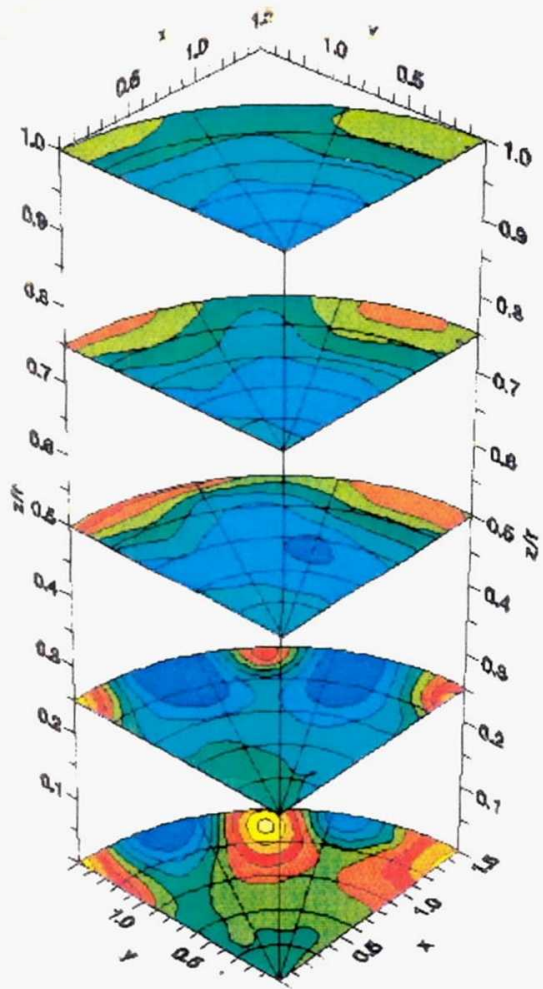

above 0.80

$0.80-0.80$

$0.70-0.80$

$0.60-0.70$

$0.50-0.60$

$0.40-0.50$

$0.30-0.40$

$0.20-0.30$

$0.10-0.20$

below 010
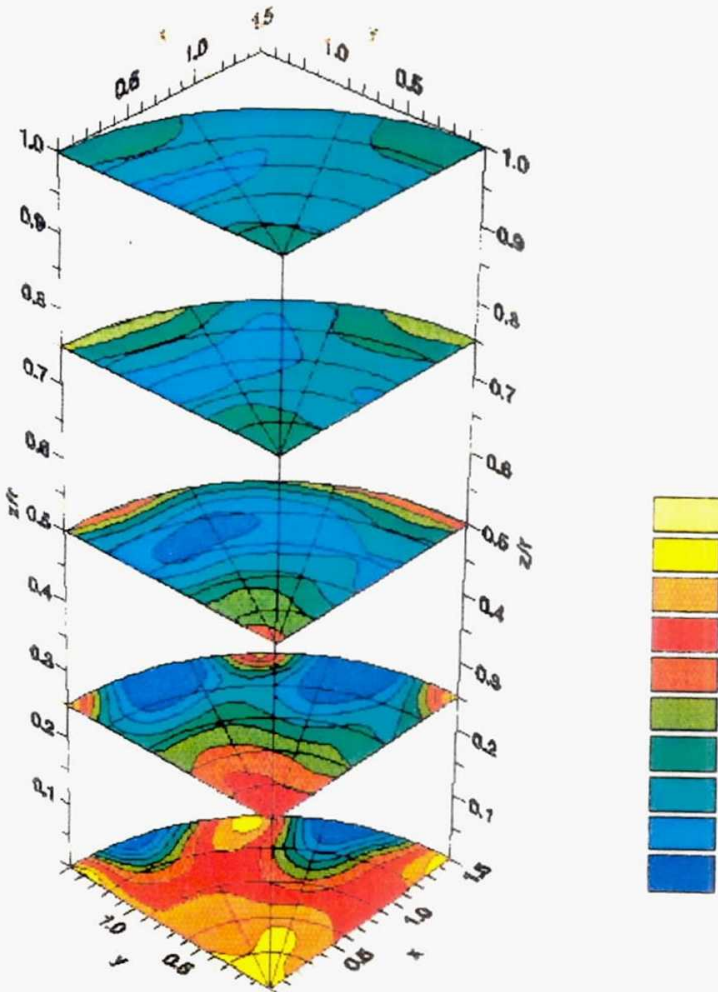

above 0.90

$0.80-0.90$

$0.70-0.80$

$0.60-0.70$

$0.50-0.60$

$0.40-0.50$

$0.30-0.40$

$0.20-0.30$

$0.10-0.20$

belaw 0.10

Figure 7: Mixture Fraction, J25MOD1, Baseline 8-Hole, J=26.7

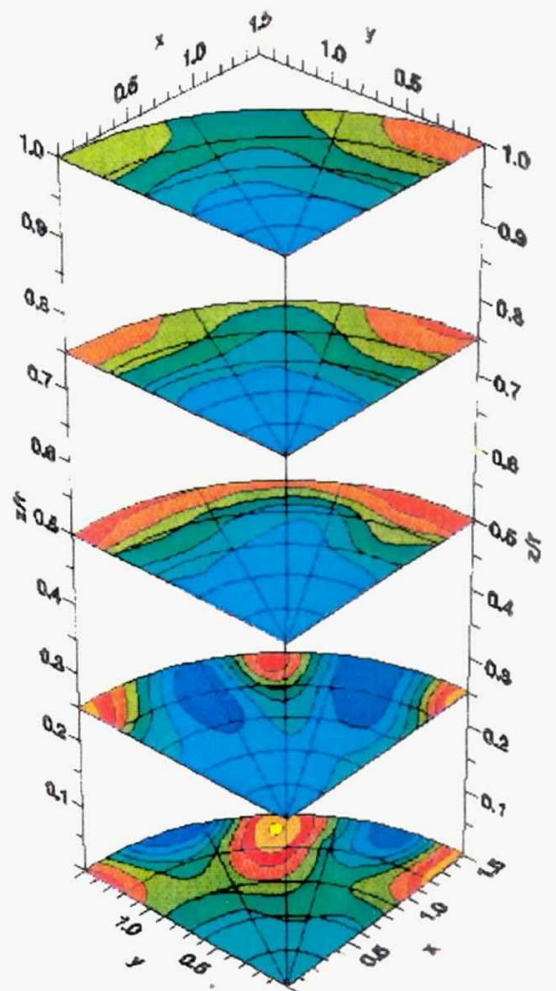

above 0.90

$0.80-0.90$

$0.70-0.80$

$0.60-070$

$0.50-0.60$

$0.40-0.50$

$0.30-0.40$

$0.20-0.30$

0.10 - 0.20

below 0.10

Figure 8: Mixture Fraction, J52MOD1, Baseline 8-Hole, J=55.4

Figure 9: Mixture Fraction, J80MOD1, Baseline 8-Hole, J=84.2 
Page intentionally left blank 


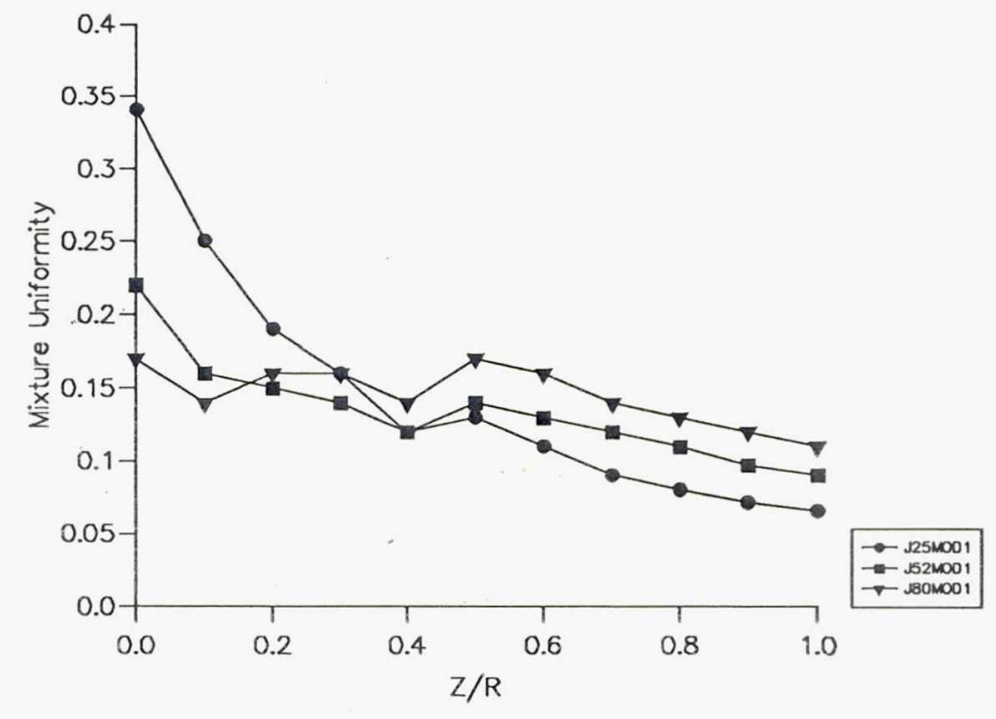

Figure 10: Mixture Uniformity for Baseline Modules
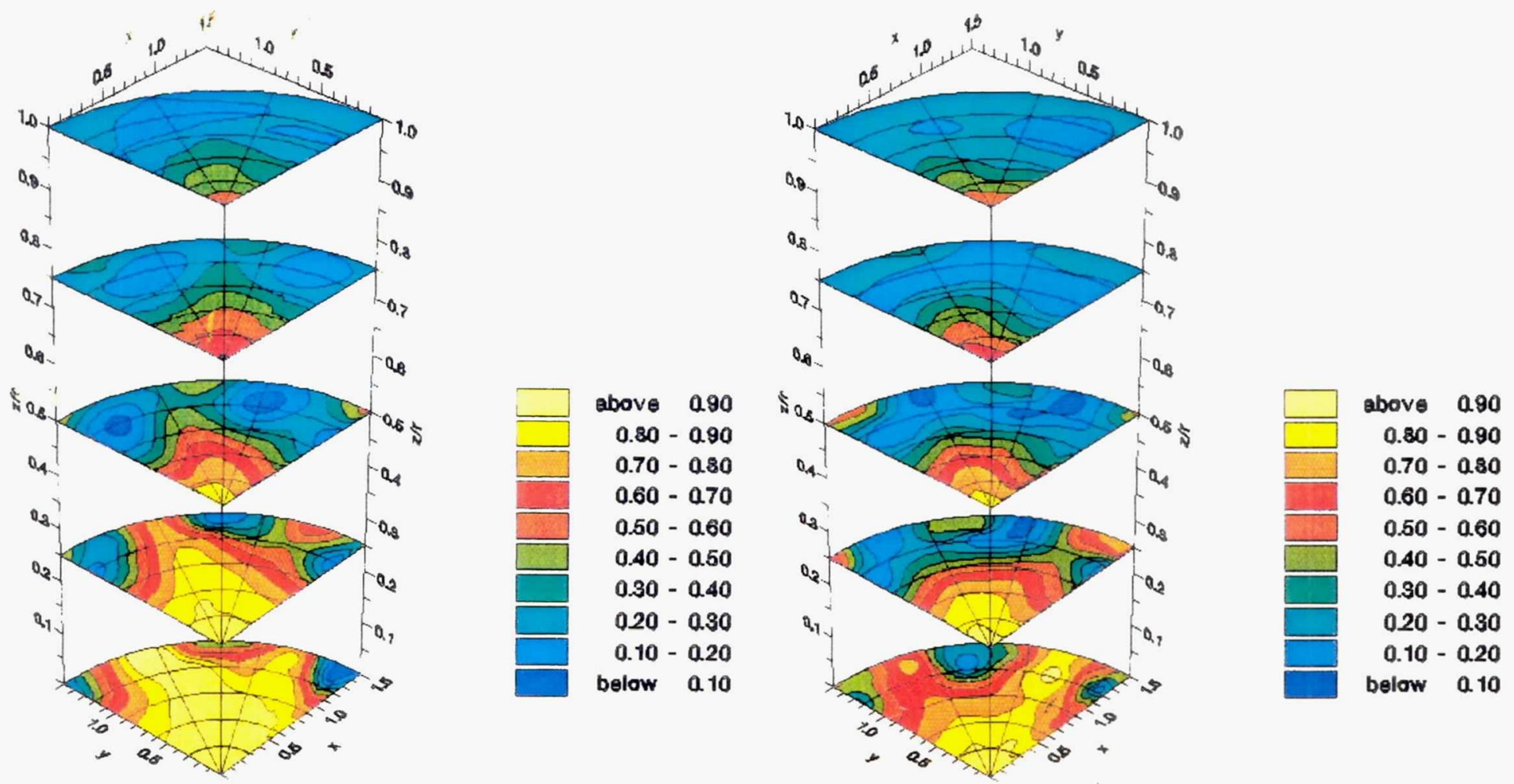

Figure 11: Mixture Fraction, J25MOD2, 8:1 Aspect Ratio Slanted Slots, J=28.1

Figure 12: $\quad$ Mixture Fraction, J52MOD2, 8:1 Aspect Ratio Slanted Slots, J=50.9 
Page intentionally left blank 


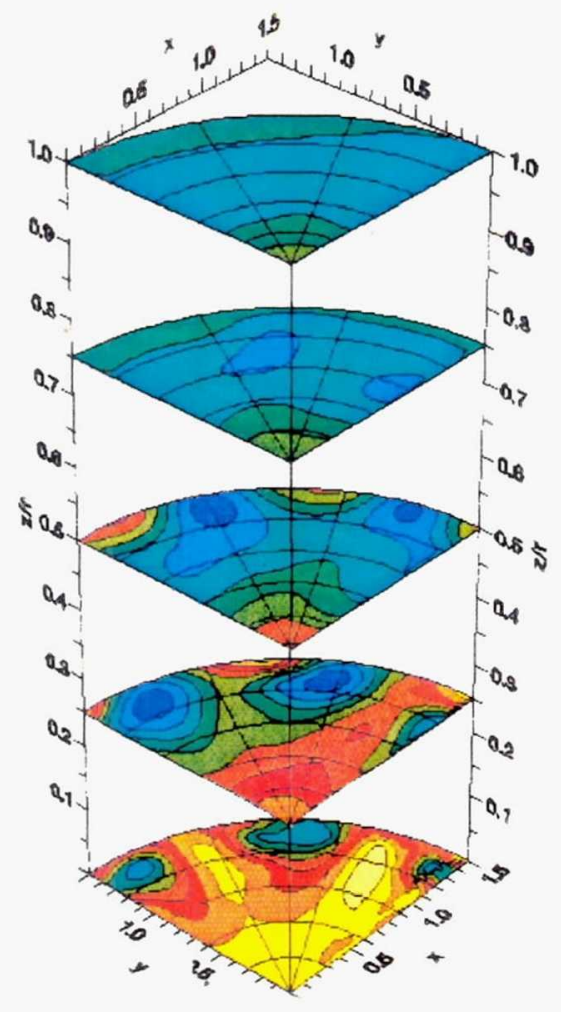

Figure 13: Mixture Fraction, J80MOD2, 8:1 Aspect Ratio Slanted Slots, J=88.5

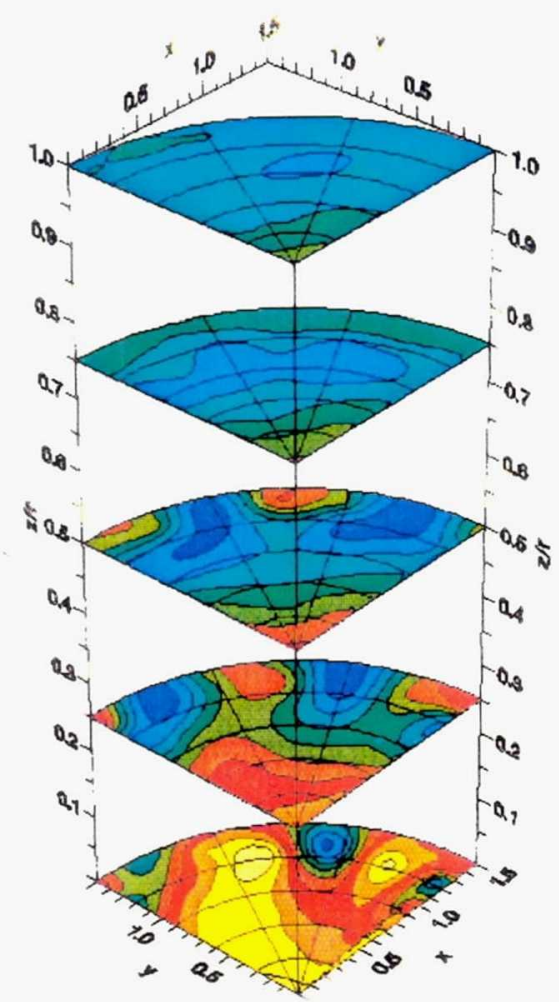

Figure 15: Mixture Fraction, J25MOD5, 4:1 Aspect Ratio Slanted Slots, J=30.5

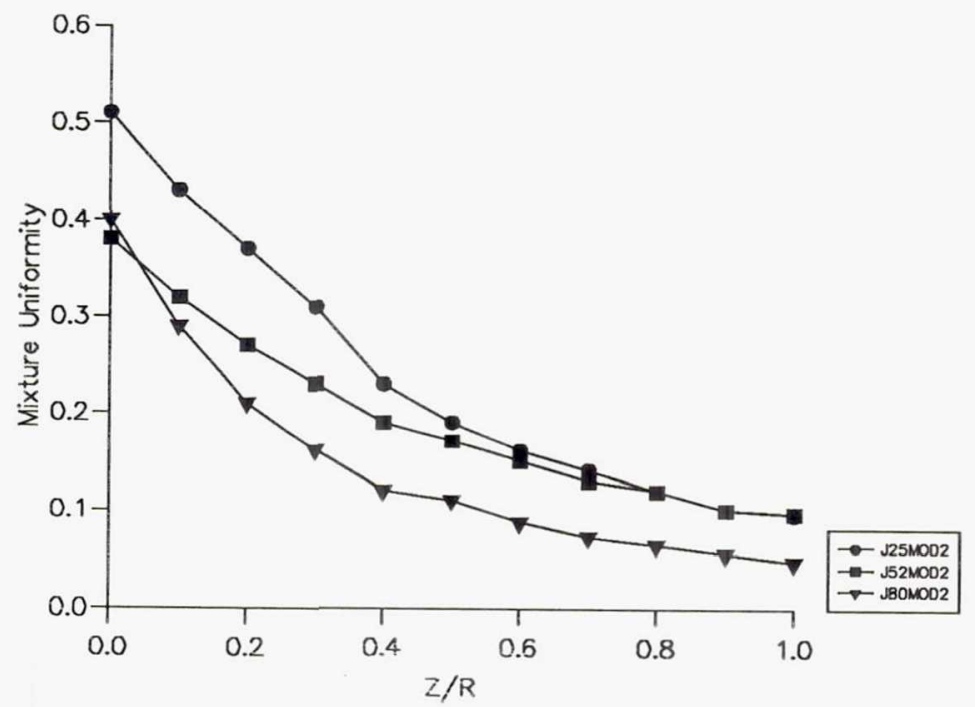

Figure 14: Mixture Uniformity for 8:1 Aspect Ratio Modules
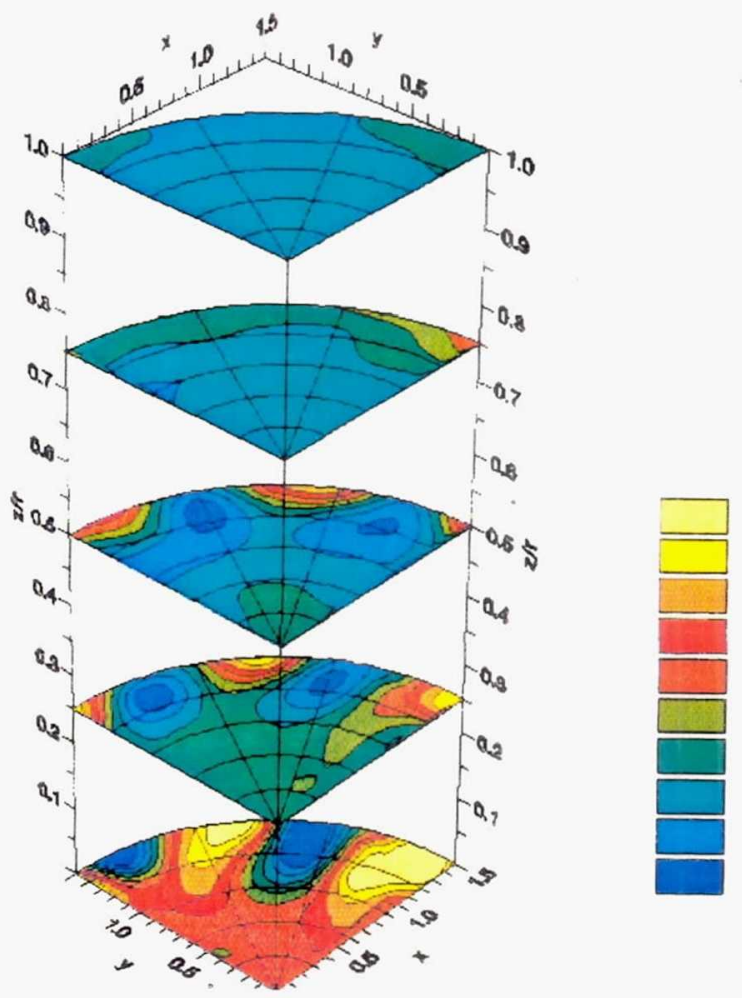

above 0.90

$0.80-0.90$

$0.70-0.80$

$0.60-0.70$

$0.50-0.60$

$0.40-0.50$

$0.30-0.40$

$0.20-0.30$

$0.10-0.20$

below 0.10
Figure 16: $\quad$ Mixture Fraction, J52MOD5, 4:1 Aspect Ratio Slanted Slots, J=57.7 
Page intentionally left blank 


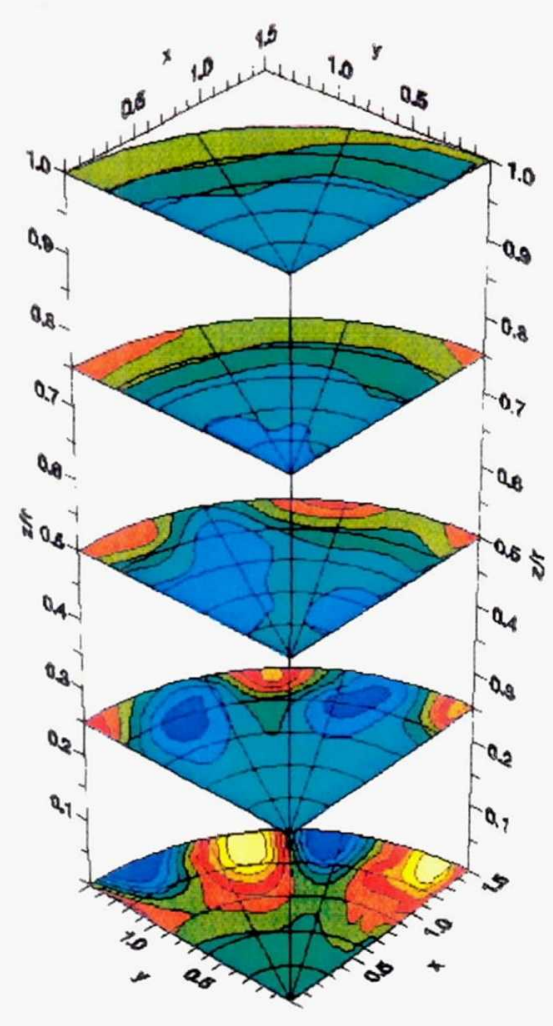

Figure 17: $\quad$ Mixture Fraction, J80MOD5, 4:1 Aspect Ratio Slanted Slots, J=93.0

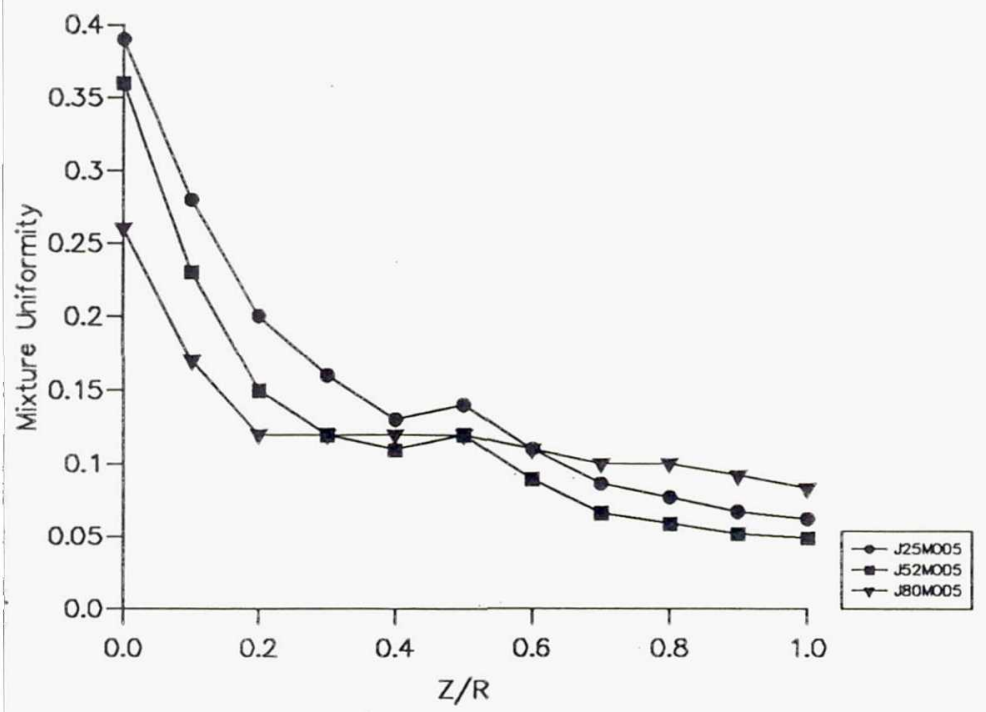

Figure 18: Mixture Uniformity for 4:1 Aspect ratio Modules
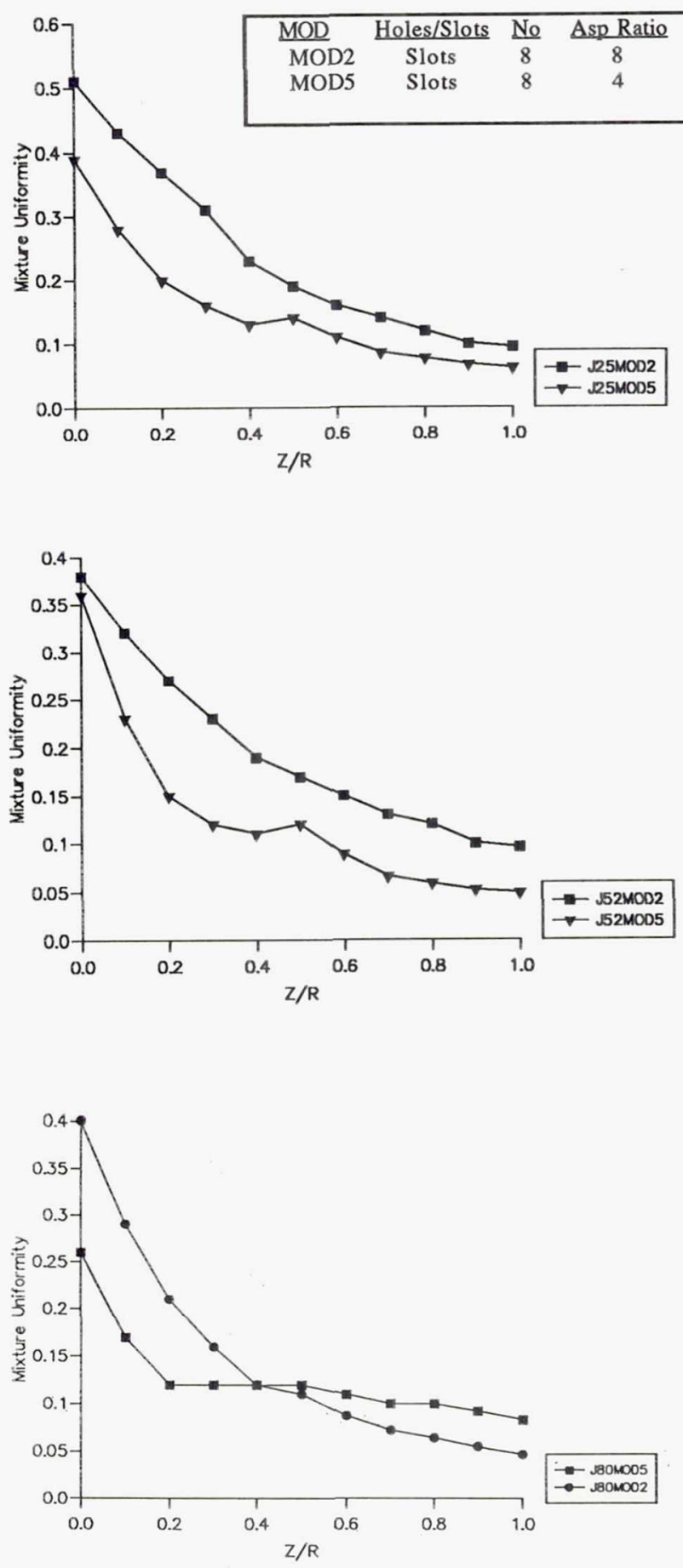

Figure 19: Effect of Slot Aspect Ratio on Mixture Uniformity 
Page intentionally left blank 


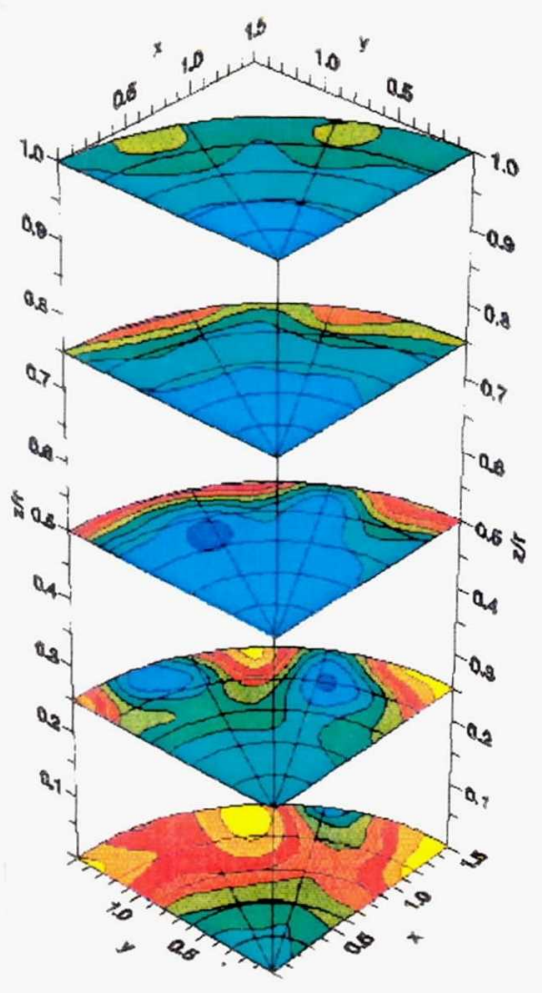

Figure 20: $\quad$ Mixture Fraction, J52MOD3, 4:1 Aspect Ratio Slanted Slots, Angle $=0^{\circ}, \mathrm{J}=51$

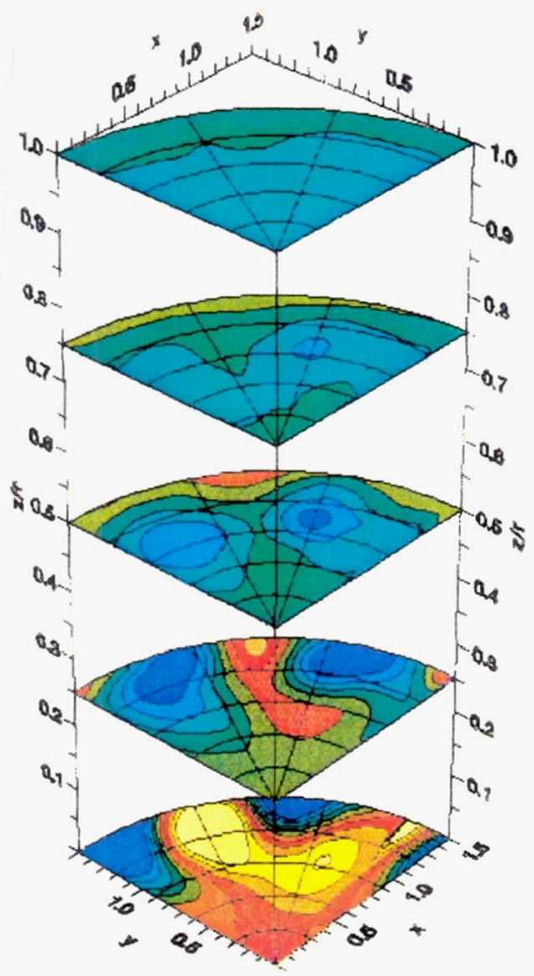

Figure 22: $\quad$ Mixture Fraction, J52MOD6, 4:1 Aspect Ratio Slanted Slots, Angle $=67.5^{\circ}, \mathrm{J}=60$
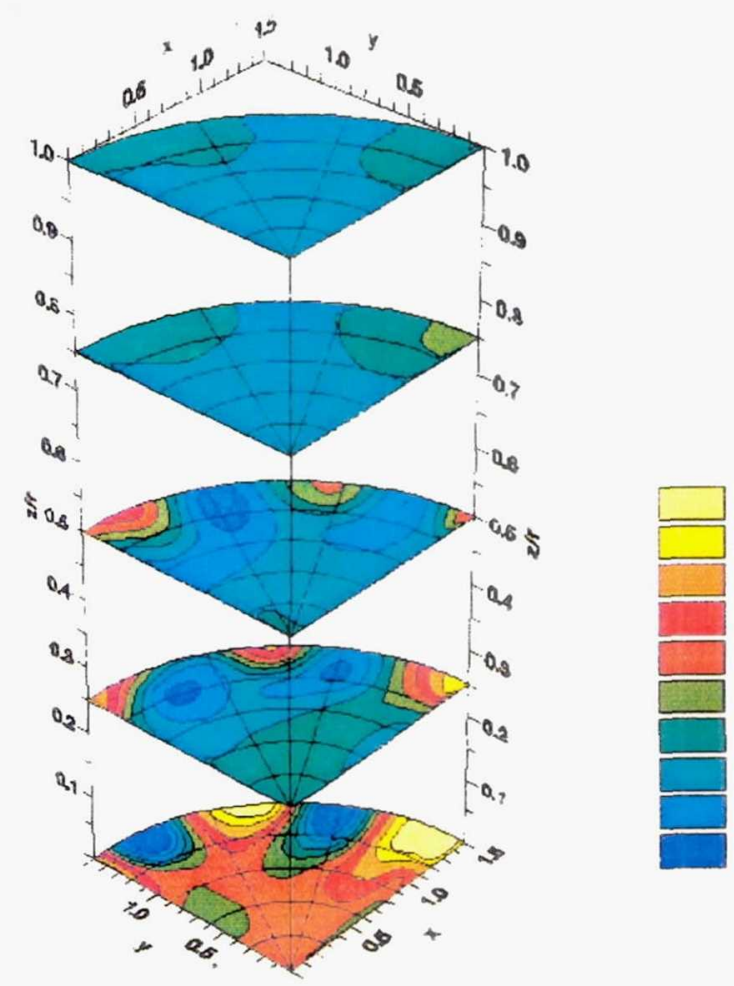

above 0.90

$0.80-0.90$

$0.70-0.80$

$0.60-0.70$

$0.50-0.60$

$0.40-0.50$

$0.30-0.40$

$0.20-0.30$

$0.10-0.20$

below a.10
Figure 21: $\quad$ Mixture Fraction, J52MOD4, 4:1 Aspect Ratio Slanted Slots, Angle $=22.5^{\circ}, \mathrm{J}=53$

\begin{tabular}{|ccccc|}
\hline MOD & Holes/Slots & $\frac{\text { No }}{\text { Hosp Ratio }}$ & Angle \\
J52MOD3 & Slots & 8 & 4 & 0 \\
J52MOD4 & Slots & 8 & 4 & 22.5 \\
J52MOD5 & Slots & 8 & 4 & 45 \\
J52MOD6 & Slots & 8 & 4 & 67.5 \\
& & & & \\
\hline
\end{tabular}

above 090

$0.80-0.90$

$0.70-0.80$

$0.60-0.70$

$0.50-0.60$

$0.40-0.50$

$0.30-0.40$

$0.20-0.30$

$0.10-0.20$

below a 10

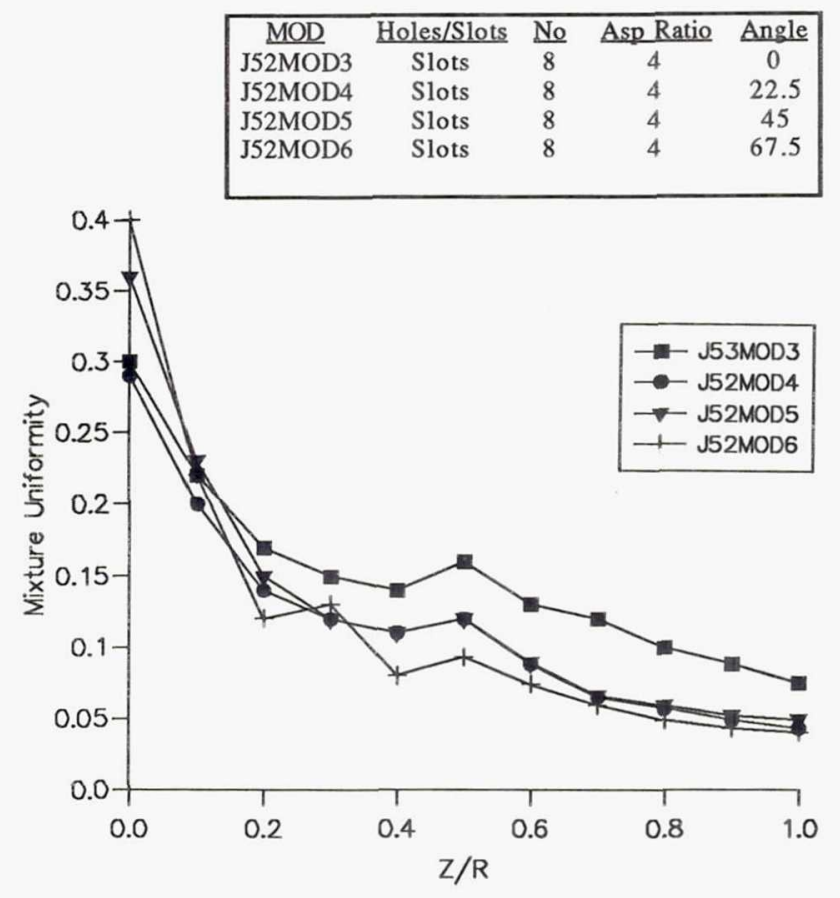

Figure 23: Effect of Slot Angle on Mixture Uniformity 
Public reporting burden for this collection of information is estimated to average 1 hour per response, including the time for reviewing instructions, searching existing data sources, gathering and maintaining the data needed, and completing and reviewing the collection of information. Send comments regarding this burden estimate or any other aspect of this collection of information, including suggestions for reducing this burden, to Washington Headquarters Services, Directorate for information Operations and Reports, 1215 Jefferson Davis Highway, Suite 1204, Arlington, VA 22202-4302, and to the Office of Management and Budget, Paperwork Reduction Project (0704-0188), Washington, DC 20503.

\begin{tabular}{|l|l|r|}
\hline 1. AGENCY USE ONLY (Leave blank) & $\begin{array}{r}\text { 2. REPORT DATE } \\
1992\end{array}$ & $\begin{array}{r}\text { 3. REPORT TYPE AND DATES COVERED } \\
\text { Technical Memorandum }\end{array}$ \\
\hline
\end{tabular}

4. TITLE AND SUBTITLE

5. FUNDING NUMBERS

Jet Mixing Into a Heated Cross Flow in a Cylindrical Duct: Influence of

Geometry and Flow Variations

6. $\operatorname{AUTHOR}(\mathrm{S})$

WU-537-02-20

M.S. Hatch, W.A. Sowa, G.S. Samuelsen, and J.D. Holdeman

\section{PERFORMING ORGANIZATION NAME(S) AND ADDRESS(ES)}

National Aeronautics and Space Administration

Lewis Research Center

Cleveland, Ohio 44135-3191

9. SPONSORING/MONITORING AGENCY NAMES(S) AND ADDRESS(ES)

National Aeronautics and Space Administration

Washington, D.C. 20546-0001
8. PERFORMING ORGANIZATION REPORT NUMBER

E- 6780

10. SPONSORING/MONITORING AGENCY REPORT NUMBER

NASA TM - 105390

AIAA-92-0773

11. SUPPLEMENTARY NOTES

Prepared for the 30th Aerospace Sciences Meeting and Exhibit sponsored by the American Institute of Aeronautics and Astronautics, Reno, Nevada, January 6-9, 1992. M.S. Hatch, W.A. Sowa, and G.S. Samuelsen, University of California, UCI Combustion Laboratory, Irvine, California 927173550 (work funded under NASA Grant NAG3-1110); J.D. Holdeman, NASA Lewis Research Center. Responsible person, J.D. Holdeman, (216) 433-5846.

12a. DISTRIBUTION/AVAILABILITY STATEMENT $\quad$ 12b. DISTRIBUTION CODE

Unclassified - Unlimited

Subject Category 07

\section{ABSTRACT (Maximum 200 words)}

To examine the mixing characteristics of jets in an axi-symmetric can geometry, temperature measurements were obtained downstream of a row of cold jets injected into a heated cross stream. Parametric, non-reacting experiments were conducted to determine the influence of geometry and flow variations on mixing patterns in a cylindrical configuration. Results show that jet to mainstream momentum flux ratio and orifice geometry significantly impact the mixing characteristics of jets in a can geometry. For a fixed number of orifices, the coupling between momentum flux ratio and injector geometry determines (1) the degree of jet penetration at the injection plane, and (2) the extent of circumferential mixing downstream of the injection plane. The results also show that, at a fixed momentum flux ratio, jet penetration decreases with (1) an increase in slanted slot aspect ratio, and (2) an increase in the angle of the slots with respect to the mainstream direction.

14. SUBJECT TERMS

Dilution; Jet mixing flow; Gas turbines; Combustion chamber; Can; Emmisions 17. SECURITY CLASSIFICATION
OF REPORT

Unclassified
18. SECURITY CLASSIFICATION OF THIS PAGE Unclassified
19. SECURITY CLASSIFICATION OF ABSTRACT

Unclassified 